\title{
Simulation model of a protection scheme for active distribution networks
}

\author{
F. Belloni ${ }^{1}$, C. Chiumeo ${ }^{1}$, C. Gandolfi ${ }^{1}$, S. Pugliese ${ }^{2}$ \\ ${ }^{1}$ Ricerca sul Sistema Energetico - RSE S.p.A. \\ Via Rubattino 54, 20134, Milano (Italy) \\ Phone number:+39 0239925796 \\ ${ }^{2}$ A2A Reti Elettriche S.p.A. \\ Via Ponte Nuovo 100, 20128, Milano (Italy) \\ Phone number:+39 0277205605 \\ e-mail: belloni@rse-web.it, Riccardo.Chiumeo@rse-web.it, Chiara.Gandolfi@rse-web.it, salvatore.pugliese@a2a.eu
}

\begin{abstract}
The growing trend of installed power from Distributed Generators (DG) in distribution networks is giving rise to new issues in grid operations. In particular, the interaction between DG and grid protections can cause nuisance trips, unwanted island operations and, in general, worsening of power quality. The paper discusses a possible protection scheme suited for active networks and implementing logic selectivity. The proposed approach is based on directional protections coordinated through communications. Simulation models of an urban Medium Voltage (MV) distribution grid, of distributed generators and of the employed types of protections have been developed in the DIgSILENT Power Factory environment. Digital simulations confirms the effectiveness of the proposed approach.
\end{abstract}

\section{Key words}

Active networks, grid protections, logic selectivity.

\section{Introduction}

A number of different drivers, such as improvements of power electronics, reduction of transmission and distribution costs, environmental issues and needs of diversifying power sources, is pushing a rapid increase of Distributed Generators (DG) connected to Medium Voltage (MV) distribution grids. The presence of large amounts of DG can interact with the grid and can have major impacts on the power quality. Some of the main interactions between DG and distribution grids are:

- Reversal of power flow;

- Harmonic pollution;

- Voltage increase;

- Voltage variations;

- Flicker;

- Nuisance trips/failures of grid protections;

- Unwanted island operations [1,2].

The paper, focusing on the last two phenomena, proposes a possible protection scheme suited for active distribution grids [3]. Such a scheme makes use of directional line overcurrent relays and directional earth relays and introduces communications among grid protections and interface protections of DG [4]. The main goals of the proposed solutions are: management of bidirectional power flows, logic selectivity, faulty line segment selection, reduced risk of unwanted island.

The paper deals with the implementation in the DIgSILENT $^{1}$ Power Factory digital simulation environment of the proposed protection scheme. To this purpose, models of a typical urban MV distribution grid, of grid protections, of DG interface protections and of the communications systems have been developed. Digital simulations were performed to show the effectiveness of the proposed solution.

\section{Operation principles of the protection scheme}

The protection scheme typically employed in a MV distribution feeder is based on a main protection, including an overcurrent relay (non-directional) and a directional earth relay, installed at the primary substation level together with a circuit breaker [5]. In case of fault along the line, the protection trips disconnecting the whole feeder from the main grid. In order to reduce the risk of unwanted island operations, each generator is equipped with an interface protection, which trips in case of under/over-voltage or frequency variations larger than a dead band around the nominal value.

The main drawbacks of this protection scheme are:

- Disconnection of the entire feeder in case of fault;

- Possible disconnection of generators also in nonfaulted lines;

- Possible unwanted island operation (the interface protection does not recognize the loss of main);

- Reclosure procedures affecting the whole feeder. In the proposed protection scheme, the distribution feeder is instead subdivided into two or more segments. A line protection and a circuit breaker are installed at the beginning of each line segment. Each protection is composed by a directional line overcurrent relay and a

\footnotetext{
${ }^{1}$ DIgSILENT Power Factory, version 14.1.4.
} 
directional earth relay. Line protections can exchange messages, and, in particular, two different logic commands can be sent/received:

- BLOCK: the receiving protection is disabled, so that it cannot trip;

- TRIP: the receiving protection is forced to trip, independently of its settings.

Also DG interface protections should be modified to be adapted. In particular, they should accept TRIP commands and they should provide two different dead bands around the frequency nominal value, as shown in Fig. 1.
The wider dead band is employed in standard conditions, while the narrower is automatically activated only in case the fault is located near the generator [6].

The operation principles of the proposed protection scheme are illustrated in Fig. 2. Two directional protections, one for each possible direction, are installed at the primary substation level and at the secondary substations, as shown in Fig. 2. In the example, a fault occurs in the second line segment.

Protections P0 and P1B start due to fault current supplied by the primary substation; P2A (and P3A, if the line has more segments than in Fig. 2) also possibly starts, due to the fault current supplied by DG2.

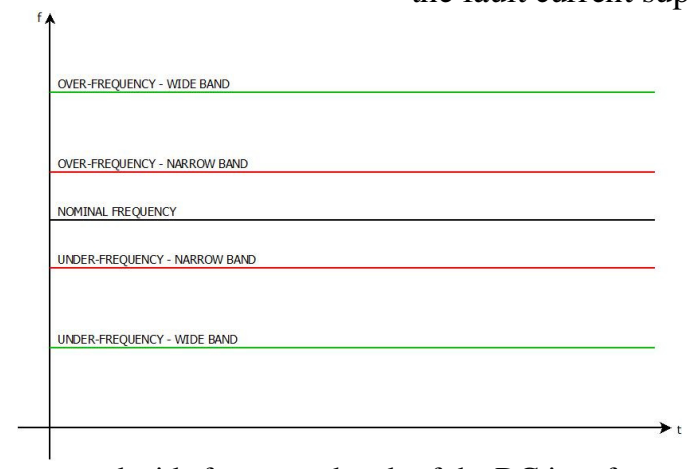

Fig. 1. Narrow and wide frequency bands of the DG interface protections.

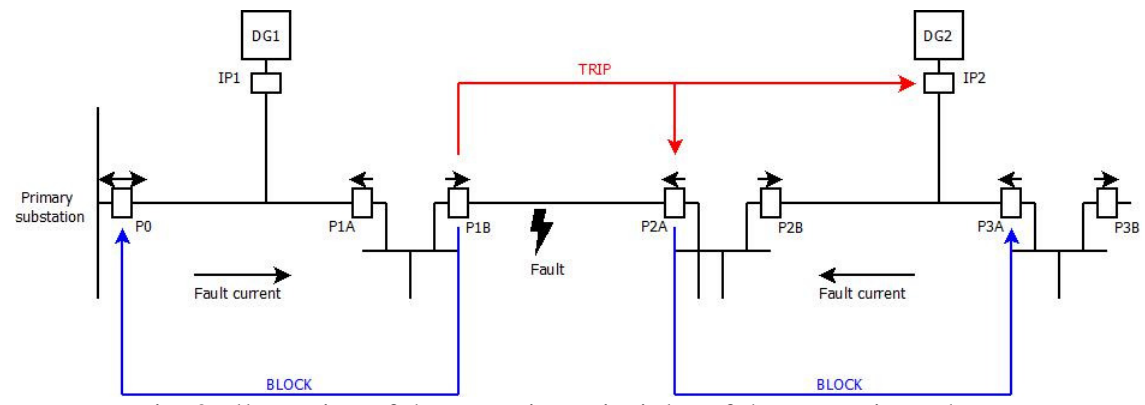

Fig. 2. Illustration of the operation principles of the protection scheme.

In the proposed scheme:

1. P1B send a BLOCK message to $\mathrm{P} 0$, i.e. in the opposite direction to respect to the fault current; the same holds for P2A and P3A;

2. P0 and P3A, being blocked, do not trip, while $\mathrm{P} 1 \mathrm{~B}$ and P2A can trip;

3. if $\mathrm{P} 1 \mathrm{~B}$ is the first protection that trips, it sends a TRIP signal to P2A which is forced to trip too;

4. a TRIP signal is sent to all DG connected downstream P1B, forcing disconnections.

In such a way, the fault is unsupplied and the faulted line segment is detected by the tripping of $\mathrm{P} 1 \mathrm{~B}$ and $\mathrm{P} 2 \mathrm{~A}$. The line segments upstream the faulted one remain supplied and the relevant DG remain connected if it has Fault Ride Through (FRT) capability. In case of communication failure, the protection $\mathrm{P} 0$ does not receive the BLOCK signal and trips, disconnecting the whole distribution feeder. In such a way, the protection scheme is still functional, even though with reduced performances ${ }^{2}$.

The proposed protection scheme has two main drawbacks:

- Protection set up must take into account communication time delays;

\footnotetext{
${ }^{2}$ In this case, performances are the same as those of "present" protection system.
}

- Protections and circuit breakers should be duplicated along the line to reduce the load disconnected (Fig. 2).

\section{Simulation models}

For the study presented in the paper, the following DIgSILENT Power Factory simulation models have been developed:

- MV distribution grid;

- Distributed Generators;

- Directional line protections and directional earth protections;

- DG interface protections;

- Communication channels with adjustable delays.

\section{B. Distribution grid}

The scheme of an urban MV distribution network of the Italian DSO A2A Reti Elettriche S.p.A. has been considered. Even though quite general, the selected network has some peculiarities, such as the presence of a $23 \mathrm{kV}$ level and a $9 \mathrm{kV}$ level and the connection of two $23 \mathrm{kV}$ busbars with eight parallel lines. The network scheme is represented in Fig. 3, where each voltage level is represented with a different colour (GREEN: $9 \mathrm{kV}$, RED: $23 \mathrm{kV}$, BLUE: $220 \mathrm{kV}$ ). The new type of 
directional protections are installed in the two zones circled in red and green, while typical line protections are installed at the beginning of all the other distribution feeders. Also, maximum current protections are installed at the secondary side of each transformer. The neutral point of the MV network is not connected to earth.

\section{Distributed generators}

Photovoltaic distributed generation is considered in the study. DiGSILENT native models of PV generators are employed, with custom controls. In particular, during steady state, PV generators supply their rated power, while during a voltage dip they supply reactive current $\Delta \mathrm{I}_{\mathrm{q}}$ proportional to the voltage drop $\Delta \mathrm{V}$, according to the formula:

$$
\frac{\Delta I_{q}}{I_{N}}=k \frac{\Delta V}{V_{N}}
$$

where $I_{N}$ is the rated current, $V_{N}$ the rated voltage and $\mathrm{k} \geq 2$ [7-10]. The employed model does not take into account the presence of power electronic switches.

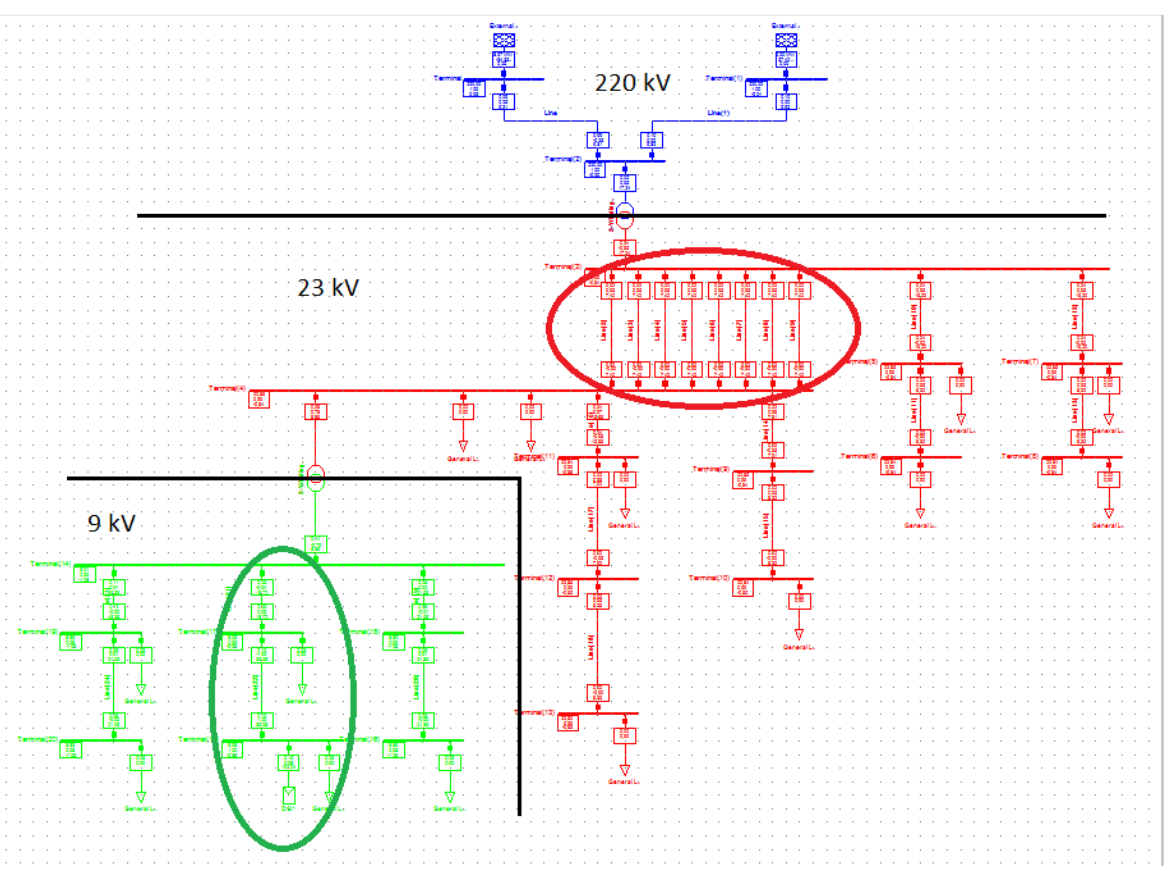

Fig. 3. DigSILENT MV network model.

\section{Directional protections}

Line protections are implemented as multifunction protections which incorporate both directional overcurrent and directional earth protections. The model, implemented within the DiGSILENT Power Factory environment, also allows the dispatch and reception of BLOCK and TRIP signals.

The directional overcurrent relay can be set up with three different current threshold levels, each one with a different time delay. The directional earth relay has a current and a voltage threshold with configurable angular sector and time delay.

The BLOCK signal is dispatched when the protection starts, while the TRIP signal when the protection actually trips.

Circuit breakers have been modelled too. In particular, a mechanical time delay of $80 \mathrm{~ms}$ between the opening command receipt and the actual opening has been considered.

\section{E. Interface protections}

The block scheme of the interface protection model is represented in Fig. 4.

According to the latest Italian standards [6], the model integrates three differwent protection functions:

- Over/under-voltage;
- Over/under-frequency (wide band) - always active;

- Over/under frequency (narrow band) - activated only if the grid voltage negative or zero sequences exceed a threshold value or the positive sequence decrease below a given limit ${ }^{3}$.

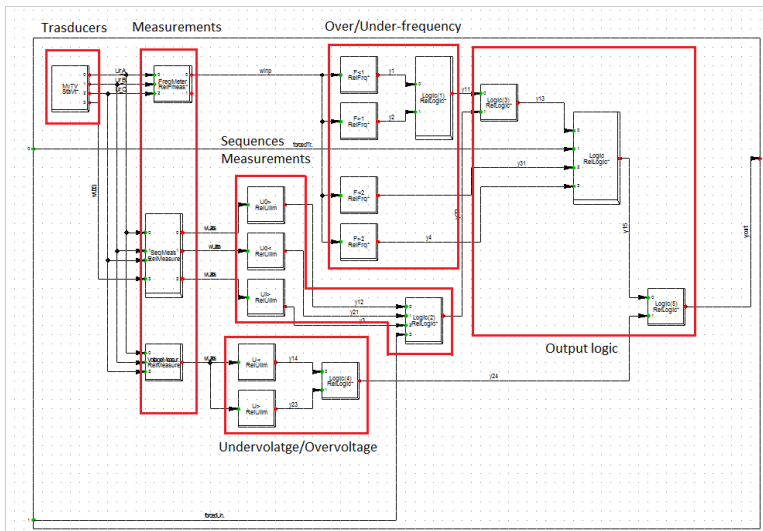

Fig. 4. DIgSILENT implementation of an interface protection.

An additional overvoltage protection should be present according to Italian standards, but it is not included in the model since it considers very slow voltage variations.

\footnotetext{
${ }^{3}$ This allows to recognize a MV fault from a frequency variation generated in the HV transmission network.
} 


\section{F. Communication channel}

Communication exchanges among protections are represented in the DIgSILENT block scheme reported in Fig. 5, where an adjustable time delay is inserted along each signal path to simulate communication lags.

\section{G. Protection settings}

Traditional line protections and DG interface protections are set according to typical Italian thresholds, as reported in Table I.

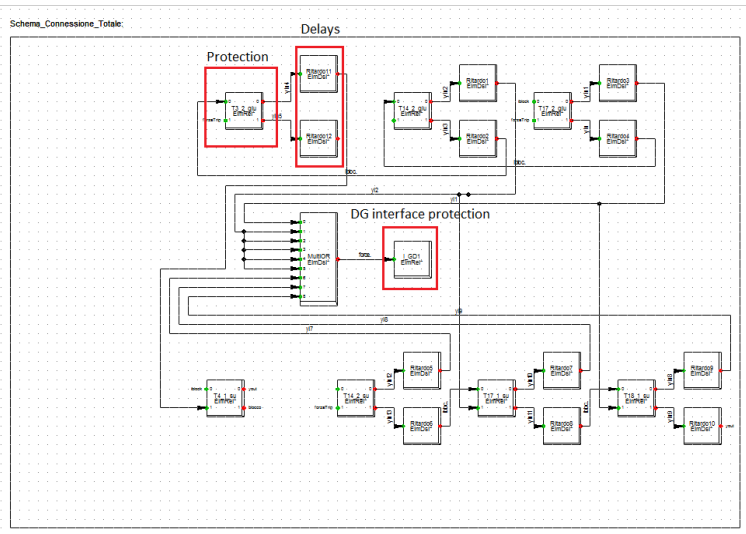

Fig. 5. Communications channel model.

Table I. Protections settings.

\begin{tabular}{|c|c|c|}
\hline Protection & Threshold & Intentional delay \\
\hline \multicolumn{3}{|c|}{ Line overcurrent @9 kV } \\
\hline 51.S1 & $1.5 \mathrm{I}_{\text {nom }}$ & $1 \mathrm{~s}$ \\
\hline $51 . S 2$ & $1 \mathrm{kA}$ & $0.25 \mathrm{~s}$ \\
\hline $51 . S 3$ & $2 \mathrm{kA}$ & $0 \mathrm{~s}$ \\
\hline \multicolumn{3}{|c|}{ Line overcurrent @23 kV } \\
\hline $51 . \mathrm{S} 1$ & $1.5 \mathrm{I}_{\text {nom }}$ & $1 \mathrm{~s}$ \\
\hline 51.S2 & $0.8 \mathrm{kA}$ & $0.25 \mathrm{~s}$ \\
\hline $51 . \mathrm{S} 3$ & $1.4 \mathrm{kA}$ & $0 \mathrm{~s}$ \\
\hline \multicolumn{3}{|c|}{ Transformer secondary side overcurrent } \\
\hline 51 & $1.6 \mathrm{I}_{\text {nom }, 2}$ & $1.5 \mathrm{~s}$ \\
\hline \multicolumn{3}{|c|}{ Directional earth@9 kV* } \\
\hline $67 \mathrm{~N}$ & $12 \mathrm{~mA}$ & $0.4 \mathrm{~s}$ \\
\hline $59 \mathrm{~N}$ & $0.4 \mathrm{~V}$ & $0.4 \mathrm{~s}$ \\
\hline \multicolumn{3}{|c|}{ Directionalearth@23kV* } \\
\hline $67 \mathrm{~N}$ & $12 \mathrm{~mA}$ & $0.4 \mathrm{~s}$ \\
\hline $59 \mathrm{~N}$ & $0.8 \mathrm{~V}$ & $0.4 \mathrm{~s}$ \\
\hline \multicolumn{3}{|c|}{ Interface protection } \\
\hline 59 & $1.15 \mathrm{~V}_{\mathrm{N}}$ & $0.2 \mathrm{~s}$ \\
\hline 27 & $0.4 \mathrm{~V}_{\mathrm{N}}$ & $0.2 \mathrm{~s}$ \\
\hline $81>. S 1$ & $50.3 \mathrm{~Hz}$ & $0.1 \mathrm{~s}$ \\
\hline $81>. S 2$ & $51.5 \mathrm{~Hz}$ & $0.1 \mathrm{~s}$ \\
\hline $81<. S 1$ & $49.7 \mathrm{~Hz}$ & $0.1 \mathrm{~s}$ \\
\hline $81<. S 2$ & $47.5 \mathrm{~Hz}$ & $0.1 \mathrm{~s}$ \\
\hline
\end{tabular}

* Settings valid also for directional earth relays of the new protection models.

The directional line relays have been set similarly to the traditional line overcurrent relay, but adding an intentional delay to the $51 . \mathrm{S} 3$ protection in order to taking into account possible communication time lags. In this paper, a typical communication time lag of $20 \mathrm{~ms}$ was supposed, so that an intentional time delay of $30 \mathrm{~ms}$ was added to the overcurrent protection. This time lag is typical of fiber optics based communications.

\section{Simulation results}

The presented protection scheme was tested through digital simulations in the DIgSILENT environment. Different case studies were considered, in order to assess both the logic selectivity among the new type of protections and the interactions with typical protection scheme. All simulations are performed adopting the network scheme of Fig. 3.

\section{A. Poly-phase fault on the line equipped with the} proposed protections scheme

A three phase short circuit was simulated on the $9 \mathrm{kV}$ line with about 2 MVA of DG connected. It is located in the second line segment, at $3 \mathrm{~km}$ from the $23 \mathrm{kV} / 9 \mathrm{kV}$ transformer. The simulation time begins at $\mathrm{t}=-100 \mathrm{~ms}$ and the fault occurs at $\mathrm{t}=0 \mathrm{~s}$. The time-overcurrent plots of the directional line protections are reported in Fig. 6 together with relevant short circuit current values.

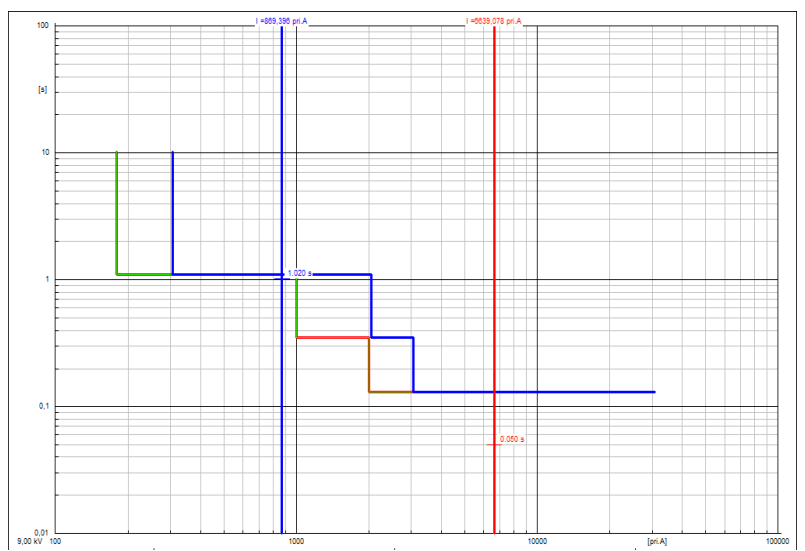

Fig. 6. Time-overcurrent plots of directional line protection. There are reported the plots relevant to protections installed at the primary substaion level (BLUE), at the beginning of the faulted line (RED) and along the same line (GREEN). Red and green curves are overlapping.

According to the plots of Fig. 6, if no logic selectivity is applied, both the protections installed on the faulted line would trip, since the short circuit current, shown as a red and a green (not visible because overlapping to the red one) vertical lines, intersects the protection characteristics at the same time value (reported on the y-axes). With the proposed approach, the protection closer to the fault is instead the only left active, minimizing the number of disconnected users. In this example, also DG are disconnected from the feeder, since they are located downstream the fault. Fig. 7 reports the following simulation results:

8a) starting status of the protection at the primary substation $(220 / 23 \mathrm{kV})$;

8b) starting status of the protection at the beginning of the MV line $(9 \mathrm{kV})$;

8c) starting status of the protection closer to the fault;

8d) blocking signal (RED) and tripping status (GREEN) of the protection at the primary substation;

8e) blocking signal (RED) and tripping status (GREEN) of the protection at the beginning of the MV line;

8f) blocking signal (RED) and tripping status (GREEN) of the protection closer to the fault. 
Only the protection closer to the fault actually trips, forcing the tripping of both the DG interface protection and of the directional line protection installed downstream the feeder. The final status of the three $9 \mathrm{kV}$ feeders is shown in Fig. 8, where the open breakers are highlighted with red circles.

The resulting voltage waveforms at different $23 \mathrm{kV}$ and 9 $\mathrm{kV}$ busbars are reported in Fig. 9, where it is shown that only the line segments downstream the fault are disconnected from the main grid. The case of single-phase fault is similar to this one and it is not reported.

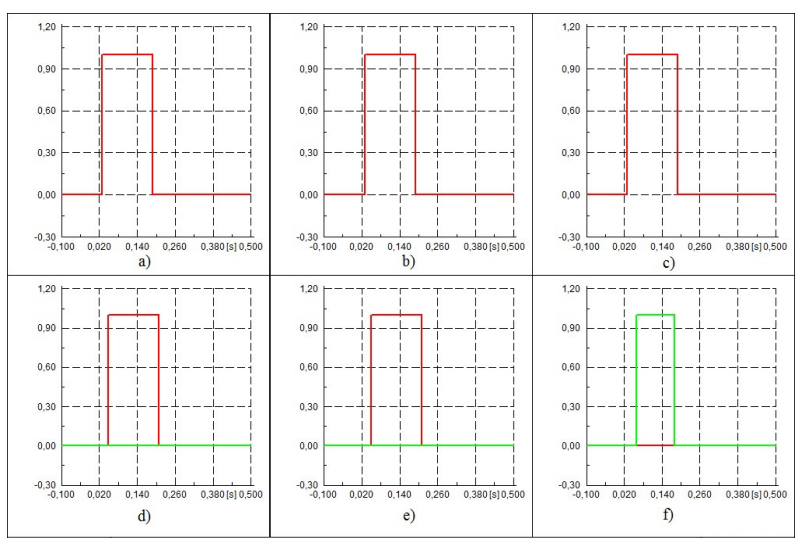

Fig. 7. Simulation results: protections starting, blocking signal exchange and protections tripping.

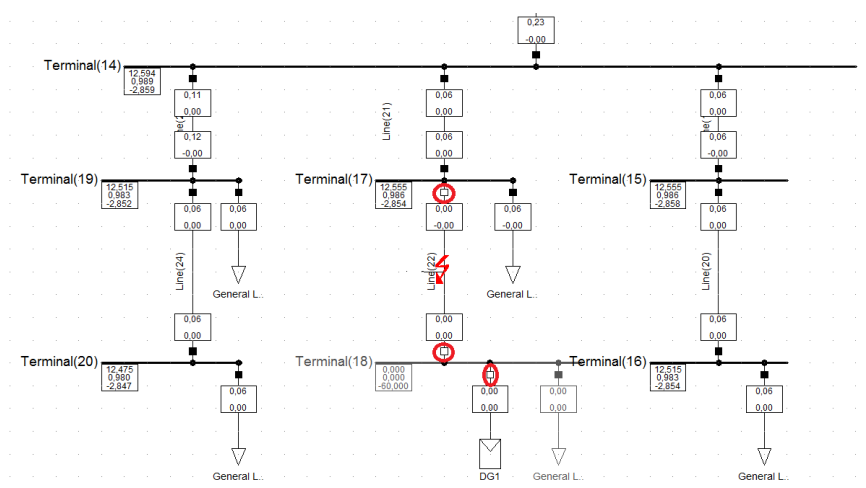

Fig. 8. Grid configuration after protections intervention. Open breakers after protection trips are highlighted with red circles.

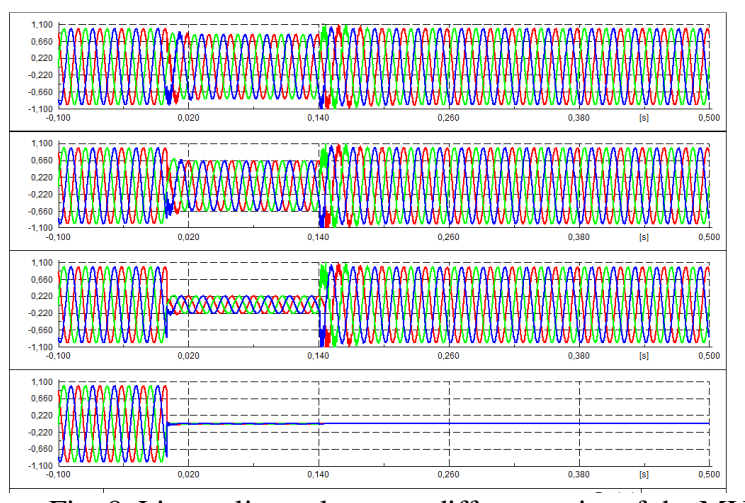

Fig. 9. Line to line voltages at different point of the MV distribution grid. a) $23 \mathrm{kV}$ primary substation busbar, b) $9 \mathrm{kV}$ busbar, c) $9 \mathrm{kV}$ line $(2 \mathrm{~km})$, d) $9 \mathrm{kV}$ line $(4 \mathrm{~km})$.

\section{B. Poly-phase fault on a line equipped with typical protections scheme}

A three phase short circuit was simulated on one of the 9 $\mathrm{kV}$ distribution line. The fault occurs at $\mathrm{t}=0 \mathrm{~s}$, at $1.5 \mathrm{~km}$ from the $9 \mathrm{kV}$ busbar. In this case, typical protection set up assures that the protection installed at the primary substation level does not trip, as shown in the timeovercurrent plots of Fig. 10.

The configuration of the $9 \mathrm{kV}$ portion of the grid after protections trip is shown in Fig. 11.

The whole faulted feeder is disconnected from the main grid, as also shown by the voltages of different MV busbars, reported in Fig. 12.

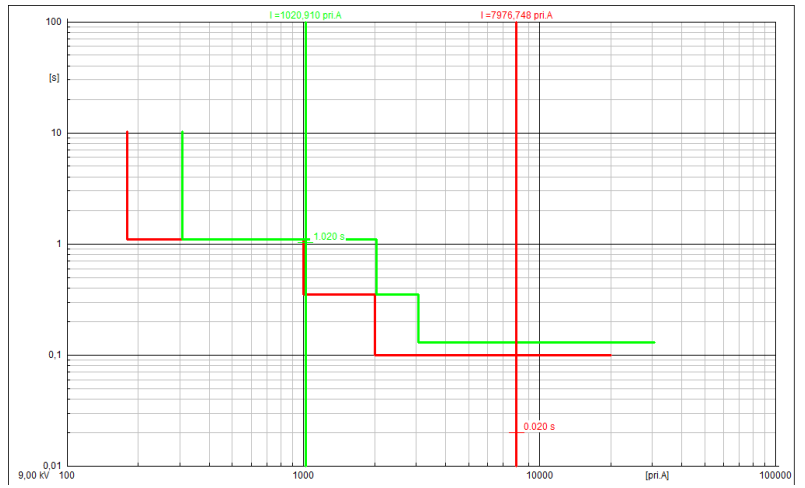

Fig. 10. Time-overcurrent plot. Primary substation protection characteristic is represented in GREEN, while $9 \mathrm{kV}$ line protection characteristic in RED.

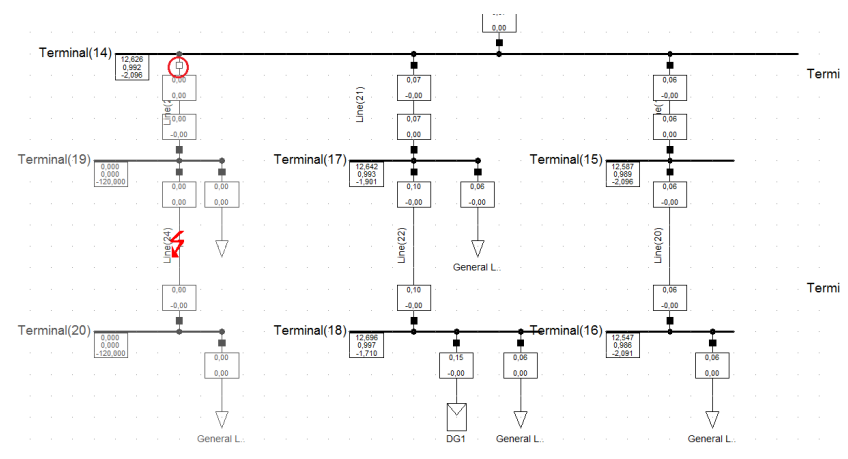

Fig. 11. Final grid configuration. Open breaker is highlighted with a red circle.

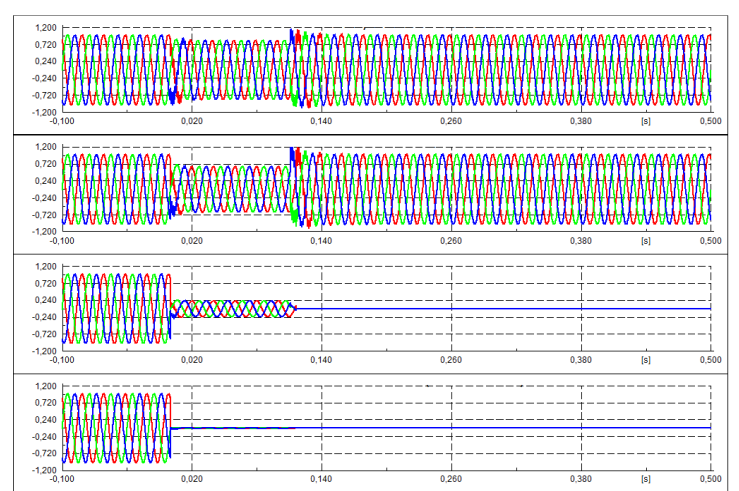

Fig. 12. line to line voltages at different point of the MV network. a) $23 \mathrm{kV}$ primary substation busbar, b) $9 \mathrm{kV}$ busbar, c) $9 \mathrm{kV}$ line $(2 \mathrm{~km})$, d) $9 \mathrm{kV}$ line $(4 \mathrm{~km})$.

In this case, DG interface protections, are not forced to trip by any external signal. The generator is equipped with FRT capabilities and it is controlled to supply reactive current during the voltage dip, according to (1). Fig. 13 reports the grid frequency and voltage measured by interface protections. Even in the case the DG current is 
sufficient to make the relevant line protection start, logic selectivity and communications avoid nuisance trips.

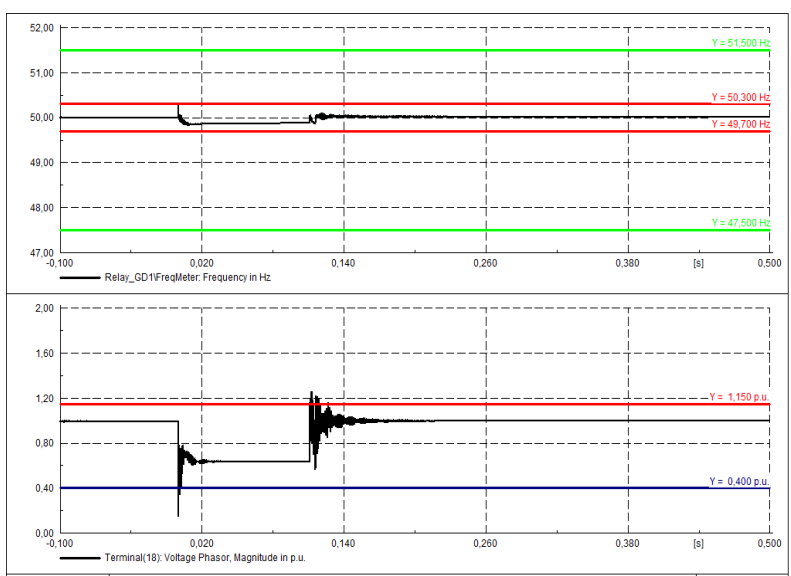

Fig. 13. Grid frequency and voltage measured by DG interface protection, compared with relevant threshold values.

\section{Poly-phase fault on a $23 \mathrm{kV}$ line}

It was simulated a three phase short circuit occurring on one of eight parallel $23 \mathrm{kV}$ lines outgoing from the primary substation MV busbar. The faulted line is selected by the trip of the protection installed at the feeder starting point which also forces the trip of the protection at the end of the line. In particular, the forced trip of this latter protection avoids the fault being supplied from the primary substation through the healthy lines. Fig. 14 shows the trip signal dispatched by the "upper" protection and received by the "lower" one, with $20 \mathrm{~ms}$ delay, and the fault currents.

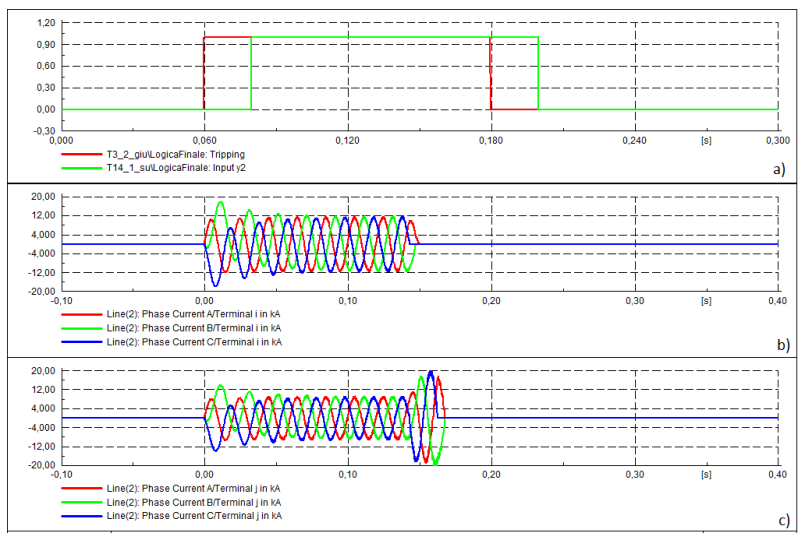

Fig. 14. Line protections coordination. a) time delay between dispatched and received TRIP signals; b) fault currents from the primary substation; c) fault currents through healthy lines.

\section{Conclusions}

A possible protection scheme suited for mixed passive and active distribution networks has been presented in the paper. It makes use of directional line relays, directional earth relays and Distributed Generators interface protections, coordinated through communications. The proposed scheme offers some advantages in terms of: logic selectivity, dealing with bidirectional power flows, optimal management of DG disconnections, faulted line segment selection, and integration with pre-existing protection schemes. On the other hand, the proposed solution has some drawbacks due to communication time lags and need of redundancy.
Digital simulations, performed with DIgSILENT Power Factory, shows the effectiveness of the proposed approach for different type of faults. For simulations, a grid model inclusive of protections and distributed generators has been developed.

Future works will deal with the analysis of the proposed protection scheme in a MV meshed network.

\section{Acknowledgement}

This work has been financed by the Research Fund for the Italian Electrical System under the Contract Agreement between RSE S.p.A. and the Ministry of Economic Development - General Directorate for Nuclear Energy, Renewable Energy and Energy Efficiency in compliance with the Decree of March 8, 2006.

\section{References}

[1] F.J. Pazos, "Operational experience and field tests on islanding event caused by large photovoltaic plants", 21th International Conference on Electricity Distribution, CIRED2011, 6-9 June, Frankfurt, Germany

[2] Z. Ye, A. Kolwalkar, Y. Zhang, P. Du, R. Walling, "Evaluation of anti-islanding schemes based on non detection zone concept", IEEE 34th Annual Power Electronics Specialist Conference, PESC '03., 15-19 June 2003, Niskayuna, NY, USA, Vol. 4, pp. 1735-1741

[3] F. Belloni, R. Chiumeo, C. Gandolfi, A. Villa, "A protection coordination scheme for active distribution networks", 47th International Universities' Power Engineering Conference, UPEC 2012, 4-7 September 2012, London, UK, pp.1-6

[4] R. Calone, A. Cerretti, A. Fatica, "Evolution of fault locator on MV distribution networks: from simple stand alone device, to a sophisticated strategic component of the SMART GRID control system", 21th International Conference on Electricity Distribution, CIRED2011, 6-9 June, Frankfurt, Germany

[5] A. Cerretti, G. Scrosati, L. Consiglio, "Upgrade of ENEL MV network automation to improve performances in presence of faults and to deal DG", 21th International Conference on Electricity Distribution, CIRED2011, 6-9 June, Frankfurt, Germany

[6] A.A.V.V., "Codice di trasmissione, dispacciamento, sviluppo e sicurezza della rete", web: http://www.terna.it/ - in Italian language

[7] R. Chiumeo, C. Gandolfi, "A Three Phase Photovoltaic Power System Connected to the MV Network: Behaviour during Voltage Dips", ICREPQ 2011, 13-15 April, Las Palmas di Gran Canaria, Spain, pp.1-6

[8] A.A.V.V., "Transmission Code 2007", web: http://www.vde.com/

[9] F:J. Pazos, "Power frequency overvoltages generated by solar plants", 20th International Conference on Electricity Distribution, CIRED2009, 8-11 June 2009, Prague, Czech Republic, pp. 1-4

[10] F. Belloni, C. Chiappa, R. Chiumeo, P. Groppelli, A. Villa, "Sistemi elettronici di potenza per la connessione della generazione distribuita alla rete elettrica: analisi del comportamento a fronte dei disturbi di rete", final report "Ricerca di Sistema", web: http://www.rse-web.it - in Italian language 